\title{
URBANIZAÇÃO E MUDANÇAS NA PAISAGEM E NOS TEMPOS DA VIDA: um estudo sobre Vitória-ES
}

\author{
URBANISATION ET DES CHANGEMENTS DANS LE PAYSAGE ET \\ DANS LE TEMPS DE LA VIE: une etude sur la ville Vitória - ES - Bresil
}

\section{URBANIZATION AND CHANGES IN THE LANDSCAPE AND IN THE TIME OF LIFE: a study in city of Vitória - Espírito Santo - Brazil}

\author{
Ana Lucy Oliveira Freire \\ Professora Adjunta do Departamento e do Mestrado em Geografia \\ Universidade Federal do Espírito Santo-UFES, Vitória-ES. \\ Rua Guaracy de Oliveira Assis, número 100, apto. 40, \\ Jardim da Penha, Vitória-ES. CEP. 29060-150 \\ alucy.freire@gmail.com
}

\section{Resumo}

Esse artigo visa analisar e debater o processo de urbanização no município de Vitória, capital e principal centro econômico do Estado do Espírito Santo, mas detidamente uma região da cidade considerada periférica e que vem passando por constantes transformações socioespaciais. A discussão fundamental do trabalho busca relacionar o processo de produção do espaço urbano e como este repercute na construção de novas paisagens e impõe mudanças na relação tempo-espaço dos moradores. Os resultados ora apresentados são fruto de procedimentos metodológicos baseados principalmente em trabalhos de campo e revisão bibliográfica, tanto teórica quanto acerca do objeto em estudo.

Palavras-Chave: Urbanização, cidadania, paisagem, cotidiano

\section{Résumé}

Cet article vise à analyser et à débattre la procédure d'urbanisation dans la ville de Vitória, le capital et le principal centre économique de l'État du Espírito Santo, mais retenuement une région de la ville considérée périphérique et qui vient en passant par de constantes transformations des sociospatiale. La discussion fondamentale du travail cherche rapporter le processus de production de l'espace urbain et comme celui-ci réverbère dans la construction de nouveaux paysages et impose des changements dans la relation l'espace-temps des habitants. Les résultats néanmoins présentés sont fruit de procédures méthodologiques basées principalement dans des travaux du champ et de la révision bibliographique, de telle façon théorique combien concernant l'objet dans étude.

Mots-Clé: Urbanisation, citoyenneté, paysage, quotidien 


\section{Abstract}

This article aims at to analyze and to debate the process of urbanization in the city of Vitória, capital and main economic center of the State of the Espírito Santo, but to focar a region of the considered city peripheral and that it comes passing for constant sociospatial transformations. The discussion paper seeks to relate the basic production process of urban space and how this affects the construction of new landscapes and requires changes in the relationship of space-time residents. The presented results however are fruit of methodologists procedures mainly based in works of field and bibliographical revision, in such a way theoretician how much concerning the object in study.

Keywords: Urbanization, citizenship, landscape, daily

\section{Introdução}

Esse texto pretende ser mais um esforço necessário à contribuição das análises e reflexões acerca do fenômeno urbano, particularmente as manifestações através das transformações urbanas pelas quais as cidades brasileiras vem passando e, nesse caso específico, acerca da cidade de Vitória, capital do estado do Espírito Santo, nosso objeto maior de pesquisa. Mas é preciso salientar que no âmbito do objeto nos instiga entender o que é e como se produz a periferia dessa cidade que é uma ilha. Portanto, nosso interesse é entender a produção do espaço "periférico".

O ponto de partida é a paisagem em mutação, as mudanças radicais na cidade e, às vezes, mudanças sutis, todas percebidas através das obras de urbanização, dos novos projetos urbanísticos, do "embelezamento", do tratamento cirúrgico visando novos espaços urbanos atrativos como parte da modernização inexorável encampada principalmente pelo estado e pelo capital via projetos, cujos objetivos na teoria são norteados pelas demandas sociais de comunidades, regiões, áreas e bairros por infraestrutura, lazer, equipamentos coletivos, melhorias, etc. Enfim, trata-se de um trabalho refletindo e apontando os aspectos comuns, as especificidades, as contradições e paradoxos inerentes ao processo de produção do espaço urbano.

Postos esses argumentos que apoiam nosso entendimento sobre o urbano a ser desvendado e esclarecido, a idéia e o objetivo desse trabalho que é parte fundamental de uma pesquisa em andamento é entender como se reproduz o espaço urbano no caso da 
cidade de Vitória, um modo de contribuir no entendimento de como vem se dando o processo de produção do urbano local. Para tanto escolhemos como objeto empírico de análise as regiões norte e noroeste da cidade, especialmente alguns fragmentos de espaço, quais sejam os bairros Andorinhas, Santa Marta, Joana D'Arc e Resistência.

A escolha desses bairros não é aleatória. Se deve ao fato de que as regiões oeste, noroeste e norte da baía de Vitória, constituem-se nas últimas áreas possíveis ao crescimento horizontal da cidade/município de Vitória, sobretudo pela transformação de mangues em solo urbano criado e incorporado à cidade, processo que teve início nos anos 70, a princípio tendo como sujeitos desse processo dezenas de famílias destituídas de tudo, migrantes de estados vizinhos e do interior do estado em busca de trabalho na região metropolitana em grande crescimento econômico/industrial. As ocupações se ampliaram nos anos 80, e na década de 90 tem início a incorporação "oficial" - pelo estado - de inúmeros novos bairros ao território da cidade, assim como as políticas e projetos públicos de urbanização/planejamento urbano, incluídos aí os processos de regularização fundiária, fundamentais para as práticas do mercado imobiliário em momento posterior.

Dividimos o texto em três partes importantes acerca do processo a que nos propomos discutir: além das palavras iniciais, a primeira parte discute a mercantilização do espaço, o segundo enfatiza e chama a atenção para as mudanças na paisagem urbana dos bairros escolhidos para a pesquisa nesse momento, mostrando tais transformações através de fotos que fazem parte de um trabalho fotográfico (sub-projeto) paralelo ao projeto, o que contribui em muito para o entendimento da paisagem; um outro momento diz respeito ao debate sobre a vida cotidiana dos moradores em transformação também.

$\mathrm{Na}$ segunda parte do artigo apontamos e tecemos algumas considerações sobre as limitações que vão se impondo ao uso do espaço à medida que os projetos de modernização - as obras de infra-estrutura e embelezamento, além da dotação de equipamentos coletivos - são implantados, o que significa a constituição de uma nova paisagem e de um outro ritmo de vida que é parte de um outro modo de vida se impondo enquanto parte do processo de homogeneização sócio-espacial por que passam as cidades.

\section{Palavras Iniciais: a produção do espaço urbano}


Nesse início de século as cidades tendem a se globalizar na medida em que são chamadas a se alinhar à economia internacionalizada inovando, ampliando sua capacidade de competição, possibilitando amplo e inovador complexo de circulação (de pessoas, de mercadorias e de capitais), desenvolvendo novas infra-estruturas, atraindo mais e diversas atividades consideradas de interesse para os ramos produtivos hegemônicos no local, os quais são os principais agentes do processo de reestruturação territorial. No intuito de atender a esse chamado, reurbaniza-se constantemente, transforma-se, moderniza-se, reinventa-se a cidade a todo momento. Trata-se, antes de mais nada, de criar, de tempos em tempos, condições locais de produção e reprodução, as quais são, também, condições globais que permitem à cidade ter hoje um papel fundamental (LIMONAD, 2002; FERNANDES, 2001; SOJA, 1993).

Nesse contexto atual do processo de globalização da economia e do novo modo de produzir capitalista denominado de pós-fordista, as cidades passam a ter papel preponderante para o crescimento das economias nacionais, regionais e locais no curso dos ajustes e adequações a fazer, e os sujeitos que mais expressam essa relevância econômica (não somente dos grandes centros urbanos, mas também de cidades médias), e trabalham para isso, são os governos locais, as prefeituras e os estados/poderes locais (BENKO, 1996; SANTOS, 2000; GOTTDIENER, 1993).

O estado nessa tarefa passa a ser, mais do que nunca antes, o idealizador, o empreendedor, o aglutinador de forças capazes de produzir o espaço. Assim, na escala do poder/governo local (mas não só nesse nível) passa-se a ver e tratar a cidade como um grande negócio ou uma "máquina de crescimento urbano" capaz de alavancar novas economias (FERNANDES, 2001). A urbanização - uma dimensão do urbano em produção - é parte dessa lógica, isto é, um espaço abstrato (fragmentado, homogêneo e hierárquico) sendo produzido pelo estado, para o estado, mas também próprio ao capitalismo enquanto estratégia de sua sobrevivência, uma vez que nesse processo estão inseridas possibilidades de reprodução das relações sociais de produção (LEFEBVRE, 1974).

Nesse sentido, faz parte da análise e do entendimento acerca do processo de produção do espaço urbano, e do próprio fenômeno urbano reflexões apontando as 
muitas transformações físicas/materiais por que passam as cidades - mas não apenas elas enquanto componentes da problemática urbana -, se a tentativa é, de fato, compreender essa realidade que se constitui no mundo moderno, mas que em parte já é concreto.

É importante ter claro as várias dimensões do urbano que se constitui. Acerca do processo de produção do espaço urbano é relevante os trabalhos de pesquisa sobre a morfologia urbana, as mudanças no nível da paisagem, a exemplo da urbanização que se perde no horizonte, transformando os bairros, os "pedaços" e regiões inteiras da cidade, além da própria metropolização. Ou seja, é relevante para a Geografia Urbana entender a urbanização enquanto crescimento (horizontal e vertical), como melhorias na infraestrutura dos lugares que fazem parte ou passam a fazer parte da cidade, a dotação de equipamentos públicos coletivos, etc,. Portanto, debruçar-se sobre essas temáticas é imprescindível no processo de desvendamento do urbano atual.

Para além da urbanização - o ponto de partida - é de grande importância no entendimento sobre a problemática que envolve o urbano, e que demanda um fôlego maior na realização das pesquisas os debates e reflexões que objetivam dar um lugar de destaque à temática da vida cotidiana, transformada, e até mesmo destruída pelo espaço abstrato que se produz pelo estado e pelo capital (LEFEBVRE, 1999). Uma vida que muda segundo o ritmo imposto pela mercantilização do espaço, enquanto parte dos projetos de modernização encampados pelo estado e atendendo a interesses do mercado. Isso quer mostrar a indissociação entre o processo de produção de um espaçomercadoria daquele que diz respeito ao processo de reprodução da vida, já que o "novo espaço" retira ou impossibilita a liberdade de usos do espaço, fator importante na prática social diária do cotidiano, por exemplo dos habitantes de um bairro. Entendemos, assim, ser esta uma outra dimensão do urbano hoje.

Está claro que o espaço urbano que se quer moderno hoje tem por finalidade última atender o mercado, isto é, os espaços se reproduzem cada vez mais em função dos interesses capitalistas/imobiliários; um espaço adequado (dominado, controlado, policiado) à fase atual do capitalismo que vê no processo de reprodução uma estratégia de lucro e, portanto, de sobrevivência como dito (LEFEBVRE, 1974). 


\section{Urbanização e Mercantilização do Espaço Urbano}

Esse capítulo ou item do trabalho tem o propósito de chamar a atenção para o processo de produção do espaço urbano em regiões e áreas da cidade de Vitória voltadas/destinadas, no momento, para abrigar as classes de pouco poder aquisitivo, isto é, são os bairros da "periferia" onde residem os trabalhadores.

O ponto de partida do trabalho é a própria paisagem atual das regiões norte e noroeste de Vitória contornada pela baía de mesmo nome, lugar que abriga muitos bairros, todos em constante transformação que se expressa sobretudo pelas diversas obras de urbanização. A análise da paisagem que ora empreendemos foca os bairros Andorinhas, Santa Marta, Joana D’Arc e Resistência, fragmentos escolhidos para o estágio atual da pesquisa, escolha esta motivada pela história de mais de duas décadas de lutas de dezenas de indivíduos buscando sanar uma necessidade básica que é morar.

A cidade de Vitória, pólo central da Região Metropolitana é, também, o menor município dessa região, além de ser toda limitada ao crescimento da mancha urbana. Trata-se de uma ilha de $81 \mathrm{~km} 2$ que já não tem mais para onde crescer horizontalmente; sua extensão territorial já foi, inclusive, ampliada com os constantes aterros transformados em solo urbano ao longo dos últimos 100 anos avançando, portanto, pelo mar, sobretudo ao longo da baía de Vitória, um dos seus limites naturais, ao sul e leste. Um outro limite natural à expansão é o que resta de significativo do manguezal que margeia a baía na regiões oeste, noroeste e norte da ilha.

A cidade-ilha encontra-se, hoje, dividida fisicamente por um maciço central que se alonga de norte a sul da ilha, transformado em parque urbano/reserva municipal. De um lado do maciço - o mais antigo - é onde concentra-se grande parte da cidade edificada, voltada para a baía e para o mar, a leste e ao sul onde as possibilidades de crescimento já se esgotaram. Nestas porções geográficas estão localizados o centro principal, as novas centralidades, os bairros que abrigam as classes de médio e alto poder aquisitivo e alguns poucos bairros que abrigam as classes de baixo poder aquisitivo. Também se esgotaram as possibilidades de criar solo urbano, isto é, os aterros que tinham que ser feitos, já aconteceram. Restaram os morros e o outro lado do maciço, a outra parte da baía e as áreas, a oeste, noroeste e norte, onde parte do 


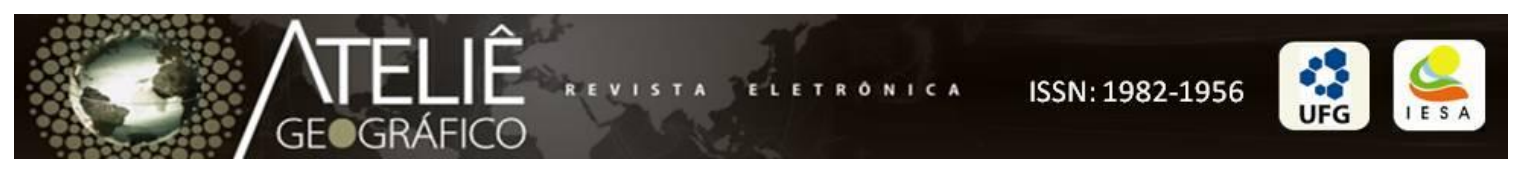

manguezal (ainda) se impõe e resiste às ocupações persistentes, onde o mangue resiste à incorporação ao solo urbano da cidade (Figura 1).

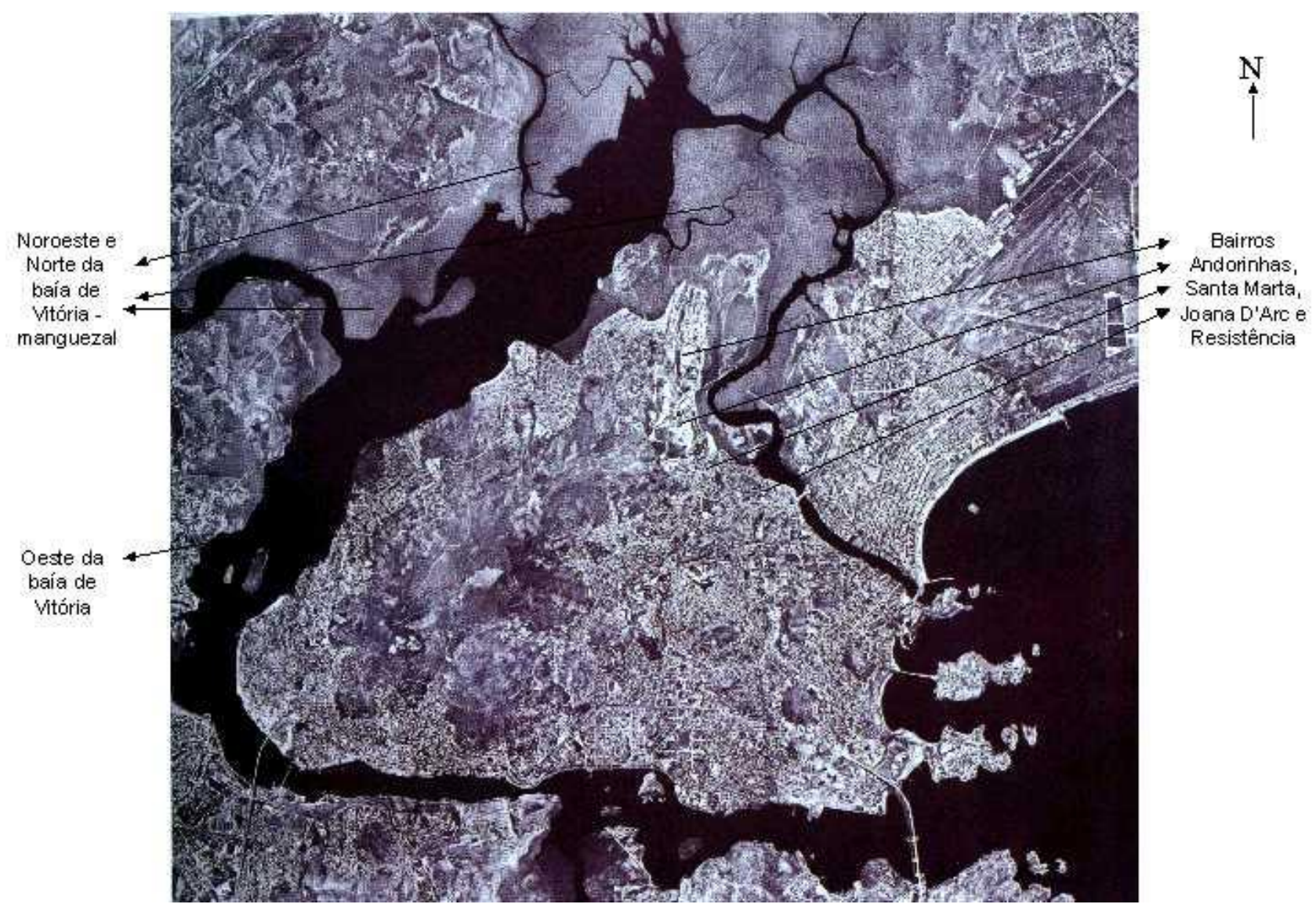

Figura 1 - Foto área da Ilha de Vitória contornada pela baía, localizando os bairros escolhidos para a pesquisa.

Fonte: Prefeitura Municipal de Vitória, 1993.

A paisagem urbana, em especial aquela da grande cidade, revela, comumente, uma confusa e complexa organização espacial da produção do espaço urbano (CARLOS, 1994). Ali se misturam coisas, pessoas, ruas em movimento, obras em andamento, ruídos de toda ordem, conflitos, trânsito caótico, etc. Do ponto de vista do que não é visível e percebido através das imagens e do que está ao alcance dos olhos - a essência das relações - estas representam outra dimensão do processo de produção do espaço urbano.

O que se transforma na paisagem urbana, e que se expressa através das formas corresponde a momentos do processo de produção do espaço urbano, segundo ritmos impostos pelo capital. Desse modo é possível compreender porque de tempos em tempos a cidade se transforma; os lugares se modificam; os bairros e os "pedaços" 


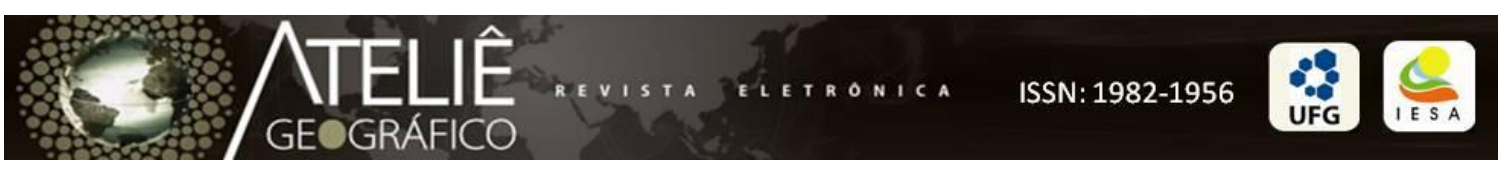

parecem ser outros, quase irreconhecíveis àqueles acostumados com uma mesma paisagem, ritmo e cotidiano.

A análise atenta da paisagem urbana possibilita, de um lado, olhar e ver o que está sendo construído, edificado; as obras arquitetônicas e urbanísticas, através de uma série de atividades. De outro, perceber e entender a vida em movimento, hoje à serviço do desenvolvimento, do progresso, do crescimento econômico que desumaniza a vida e o espaço que se reproduz. Nas palavras de Carlos (1994, p. 63), "a reprodução do espaço urbano traz em si a idéia de que a cidade cresce e o ser humano desaparece, como ser que tem vontades, desejos, idéias, enfim, que sente e que se encontra impotente diante da cidade que ele próprio produziu".

A cidade apresenta-se através da paisagem urbana como um espaço desigual evidenciado pelos diversos usos e possibilidades de usos conforme os interesses, as necessidades e as demandas dos indivíduos. Nesse processo os conflitos são inexoráveis e as diferenças resultam em contradições de classe, e mesmo entre segmentos de classe.

Pode-se dizer, nesse sentido, que os diferentes e desiguais modos de acesso à apropriação do espaço urbano resultam numa cidade toda fragmentada em "pedaços": aqui os bairros dos que podem pagar muito pela moradia, ali os bairros daqueles que tem médio poder aquisitivo da casa própria, acolá os "pedaços" dos que quase não têm renda para adquirir a residência, por entre esses áreas/terrenos ocupados, invadidos, onde surgem favelas, mais à frente, formando a periferia os loteamentos irregulares, o campo sendo transformado em solo urbano, etc.

Assim, a paisagem urbana se revela em incessante transformação; aparentando uma grande desordem porque tudo está por ficar pronto; o velho dando lugar ao novo segundo os planos e projetos de urbanização/modernização da cidade, o que exige apagar as referências, tornar tudo homogêneo eliminando o diferente. Em outras palavras, isso significa impor outro modo de vida, novo ritmo, outras formas de uso do tempo traduzindo-se em novas formas de uso do espaço conforme a lógica da reprodução, afirma Seabra (2004).

A discussão acerca do urbano hoje requer uma reflexão sobre o espaço enquanto mercadoria valorizada e largamente negociada; algo de valor e dotado de potencial para o mercado. É por isso que se faz importante a urbanização, o crescimento das cidades, os planos e políticas de modernização urbanos envolvendo diversos agentes - públicos e 
privados -, em prol da realização do capital. Daí a proliferação dos projetos de modernização por que passa muitas das cidades brasileiras, transformadas em negócios altamente rentáveis. Como afirma Damiani (2003, p. 369), “o urbano constitui uma mercadoria primordial e através de sua análise compreendemos não só o urbano, a urbanização enquanto negócio, mas também os limites, as características e a potência do movimento do capital no Brasil”.

\section{Incorporando o Mangue á Cidade}

É imprescindível nessa parte do trabalho dar conta do entendimento acerca de um modo de vida que se constitui. Trata-se de uma tentativa feita através da reflexão acerca das mudanças que resultam da urbanização, as quais constrõem/constituem espaços abstratos enquanto parte da lógica da uniformização/padronização e homogeneização generalizada a que o espaço urbano se submete. Dito de outro modo, as partes da cidade são transformados em cenários para o consumo, posto que agora são mercadorias.

$\mathrm{A}(\mathrm{s})$ onda(s) modernizantes tem por finalidade última fazer da cidade um lugar de passagem, a abstração e a alienação puras; retirar qualquer possibilidade do valor de uso se sobrepor à troca, isto é, é a extinção da vida espontânea. São essas as finalidades dos projetos urbanísticos/de urbanização pensados e implantados pelo estado ampliando o potencial do mercado que vê nesses novos espaços possibilidades de valorização imobiliária, e portanto, de novos negócios, vide os novos conjuntos de pequenos prédios populares, novas casas, ampliação das moradias/formas de aluguel, disposição de lotes, etc.

Seguindo esse raciocínio, o fundamental nesse debate diz respeito às mudanças impostas ao cotidiano, isto é, a constituição de um outro cotidiano - novos modos e formas de usar o tempo e o espaço -, um cotidiano adequado ao tempo da escassez (de tempo), do corre-corre, da pressa, da rapidez, enfim, o tempo da lógica mercantil. Se esvai, assim, uma vida baseada em relações construídas exatamente pela liberdade de uso e disponibilidade de tempo pelos indivíduos para os encontros, as festas, as conversas, a solidariedade, as trocas de experiências, a contemplação das coisas 
simples, os usos e apropriação do espaço, além da solidificação da identidade com o lugar em se vive.

Nesse processo em que a cidade é cada vez mais o lugar da produção e a vida se volta para o processo produtivo, as relações do indivíduo com o espaço se limitam ao habitar, se restringe à casa, dificultando ou impossibilitando a experiência do espaço, e a relação com o mundo no plano micro. Ou ainda como diz Carlos (2001, p. 35)

\footnotetext{
o espaço apropriável para a vida (...) o bairro, a praça, a rua, o pequeno e restrito comércio que pipoca na metrópole, aproximando seus moradores que podem ser mais do que pontos de troca de mercadorias, pois criam possibilidades de encontro e guardam uma significação como elementos de sociabilidade (...) as relações de vizinhança, o ato de ir as compras, o caminhar, o encontro, os jogos, as brincadeiras, o percurso reconhecido de uma prática vivida (...) laços profundos de identidade habitante-lugar, lugares que ganham o significado dado pelo uso marcado pela presença...
}

A velocidade com que a cidade se transforma é a razão da perda gradual da identificação do morador com o seu bairro, e com a própria cidade. O indivíduo vai estranhando o seu entorno, o que lhe era (re)conhecido, uma vez que a memória materializada nas coisas, construções, ruas, rítmo de vida, cotidiano, paisagem, etc., tendem a desaparecer.

O urbano que se constitui impõe, como já dito, um novo ritmo e novo modo de usar o tempo, como também novas formas de usar o espaço, este transformado em mercadoria. Um tempo em que tudo a ser realizado tem que ser rápido, posto que se trata do tempo para produzir coisas, mercadorias, fazer fluí-las economizando tempo, não perdendo tempo, o que elimina a possibilidade de gasto de tempo em prol de outra lógica: a do ser humano vivendo um cotidiano baseado em relações de sociabilidade.

A cidade toda fragmentada e negociada em pedaços como mercadoria tende a eliminar a possibilidade de realização do humano, posto que o lugar dessa realização é a vida cotidiana plena de relações. Quando constitui-se uma cotidianidade como parte da lógica do processo de reprodução do capital, isto é, um cotidiano que passa a ser o solo dessa reprodução, a vida social se enfraquece, assim como se percebe as mudanças no(s) espaço(s) (DAMIANI, 1997). 


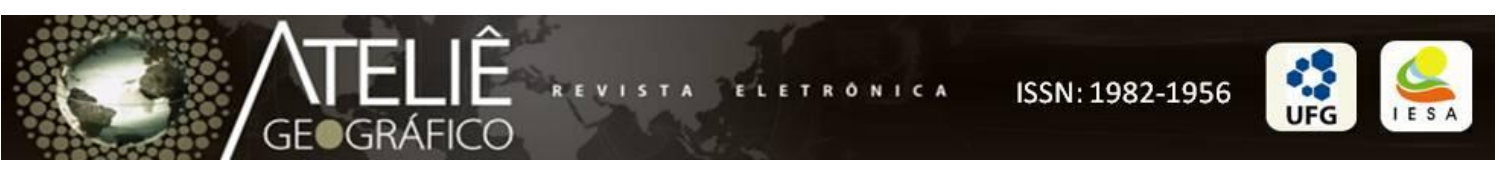

A subjetividade, as emoções, os costumes, os hábitos, os comportamentos espontâneos e as experiências como parte da vida estão incluídos no cotidiano urbano; envolvem indivíduos e grupos com o lugar em que vivem como parte dos momentos da vida social. E, quando o lugar se submete à homogeneidade do mundo modernizado, torna-se árido à apropriação para diversos usos, e é isso o que vem acontecendo nas cidades.

Esses argumentos/colocações ajudam no sentido de se reforçar a relevância que tem a noção de cotidiano urbano para entendermos a urbanização que tende a aniquilar as práticas sociais, e no caso específico que estamos pesquisando, as mudanças no tempo da vida perpassa, sobretudo, transformações ou a constituição de outro cotidiano. Segundo Seabra (2004, p. 182), “o cotidiano emerge para análise na metamorfose das formas de uso do tempo vivido; que o cotidiano urbano prolonga e explicita o sentido da urbanização capitalista pela generalização de um modo de vida noqual foram sendo aprofundadas as separações no âmbito da vida sócial".

As figuras (2, 3, 4, 5 e 6$)$ dispostas ao longo desse item representam - contém as marcas - não da evolução de uma paisagem, mas da construção/constituição de uma paisagem. Nesse caso específico, são três os principais momentos/etapas do processo: o primeiro que significa a ocupação, a conquista de um lugar para morar - as palafitas em cima do mangue; o segundo já demonstra a intervenção do estado subtraindo o mangue ao mar/construindo solo urbano, aterrando e contendo o movimento das marés e; num terceiro momento a consolidação das intervenções implantando os projetos de urbanização objetivando, dentre outros fins, a potencialização dessas áreas para o turismo.

A potencialização do espaço urbano como negócio rentável via urbanização em várias áreas a oeste e noroeste no interior da baía de Vitória, a exemplo dos bairros que escolhemos para a pesquisa - Andorinhas, Santa Marta, Joana D’Arc e Resistência -, remonta o início da ocupação dos mangues no entorno da ilha de Vitória.

A cidade de Vitória é uma ilha contornada por uma baía, a baía de Vitória. A leste a baía se encontra com o mar, e a oeste e noroeste, no interior da baía, nos deparamos com um grande manguezal formado no estuário do rio Santa Maria que desce das regiões montanhosas do estado do Espírito Santo. Os sedimentos que descem das montanhas formam um ecossistema muito rico, e por isso importante para a 
sobrevivência de muitos que ainda vivem da pesca e da cata de carangueijo e mariscos retirados do mangue, a maioria desses habitam os bairros margeados pelos mangues da baía. Antes de existirem os 11 bairros que compõem hoje a região da Grande São Pedro (uma região administrativa de Vitória), até meados do século $\mathrm{XX}$ ali existiam várias comunidades de pescadores, de lavadeiras e exploradores de cal a partir da moagem de ostras (GURGEL \& PESSALI, 2004).

A princípio a lógica era a dos moradores em busca de um lugar para morar e sobreviver após migrar do interior do estado e de outros estados para a cidade em busca de trabalho, dado o dinamismo econômico que se vislumbrava com a implantação de grandes projetos industriais na região da atual grande Vitória, a partir de meados dos anos 70 (SIQUEIRA, 2001). Trata-se, acima de tudo, de uma história de muitas lutas. Durante a segunda metade da década de 70 e por toda a década seguinte a paisagem dessas regiões, incluindo os bairros Andorinhas, Santa Marta e Resistência, era marcada pela presença de inúmeras palafitas fincadas na lama do manguezal, lixões a céu aberto e o início de alguns projetos de urbanização e de moradia criados pelos governos estadual e federal ${ }^{1}$ (figura 2).

A ausência de políticas de habitação para os trabalhadores de baixo poder aquisitivo provocou e resultou em estratégias com fins de conseguir a moradia pelos que migravam para Vitória.

Essa era a paisagem dominante ao longo das regiões oeste, noroeste e norte da baía de Vitória até a segunda metade dos anos 80, razão de vergonha para a cidade e para a sociedade local que se incomodava muito com o quadro de miséria que crescia, com a devastação dos mangues e com o descaso dos governantes em relação ao que ocorria em Vitória. A situação degradante em que viviam dezenas de famílias chegou ao ponto de chamar a atenção da mídia nacional, através da mobilização de grupos que defendiam a luta dos moradores para melhorar as condições de vida.

\footnotetext{
1 Destaca-se o programa PROMORAR, de 1979, de alguns projetos do BNH e da COHAB durante os anos 80 .
} 


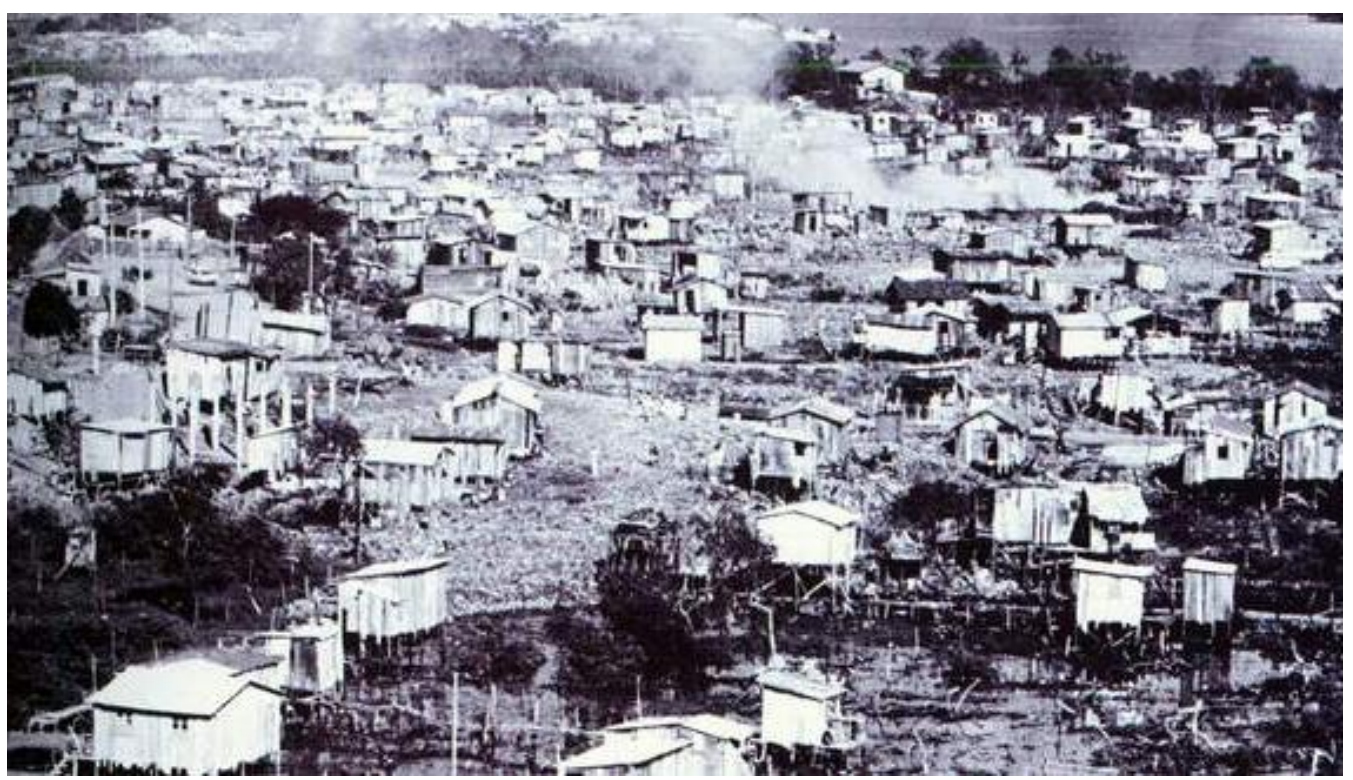

Figura 2 - Palafitas na ocupação dos mangues na década de 80.

Foto: arquivo da Prefeitura Municipal de Vitória.

No início da década de 90 teve início a grande transformação da paisagem. A mobilização dos moradores durante anos provocou a criação de políticas ${ }^{2}$ por parte da prefeitura visando a construção de melhorias na imensa região ocupada há pelo menos 15 anos. Diretrizes foram criadas, dentre as quais destacam-se a delimitação e preservação do manguezal, parcelamento do solo/limite do tamanho dos lotes, além de reassentamentos/remoções dos que ocupavam áreas de preservação e a construção de uma usina de compostagem de lixo. Todo esse processo elimina, finalmente, a paisagem dominante das palafitas.

Aumentar o espaço urbano, isto é, criar solo urbano subtraindo o mangue e conquistando a baía fazia (e ainda faz) parte dos modos e estratégias que possibilitam o crescimento dos bairros e a expansão da periferia de uma cidade-ilha; expandindo os terrenos passíveis de abrigar novas moradias, além de permitir obras de urbanização e embelezamento local. No início o lixo depositado nos lixões servia de aterro; depois a prática de aterrar passou a ser mais técnica, "profissional", usando terra extraída ou

\footnotetext{
${ }^{2}$ Faz parte de tais políticas o Projeto Terra (Programa Integrado de Desenvolvimento Social, Urbano e de Preservação Ambiental), da Prefeitura Municipal de Vitória, o qual existe com essa denominação desde 1997, e se transformou na "menina dos olhos" do governo municipal sobretudo na administrações correspondentes ao período 1996-2004.
} 
aproveitada de outros lugares da cidade, posto que desta vez já se tratava de aterros realizados pela prefeitura. Sobre essa prática, afirma Alves( 2004, p. 102):

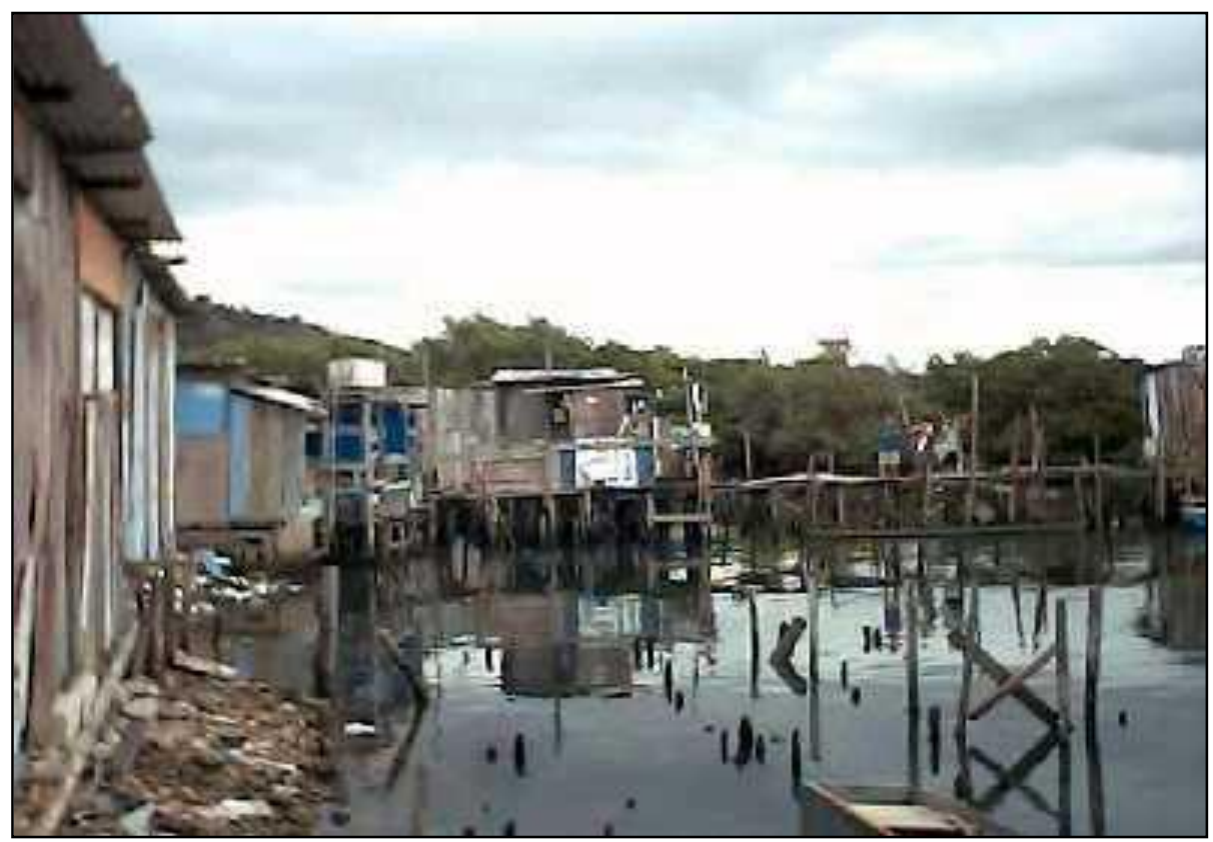

Figura 3 - Palafitas sobre o canal no bairro Santa Marta. Retiradas pela prefeitura em 2004.

Foto: André Luiz N. Coelho/2003.

Somente depois de a região da Grande São Pedro estar quase totalmente aterrada com o lixo da capital (doze anos de aterro) é que ele foi coberto com terra. Toneladas de terra foram derramadas sobre o lixo, tornando-o invisível e inexistente para o olhar de um passante, enterrando assim um triste pedaço da história de Vitória. ${ }^{3}$

E, logo, as palafitas tendiam a desaparecer e dar lugar às residências/moradias fixadas ao solo e não mais fincadas nas águas da baía; seguras, construídas em madeira ou em alvenaria, mesmo diminutas, realizando o sonho de muitos, configurando-se, assim, uma paisagem mais humana (figura 3).

Chama a atenção as mudanças oriundas da implementação de obras "modernizadoras" dos bairros escolhidos para a pesquisa, entre as quais se destacam, conforme a ordem de exposição das figuras/fotos, as quais oferecem uma idéia sobre as mudanças na paisagem. Em primeiro lugar o processo de erradicação das palafitas construídas sobre o manguezal. As famílias que ainda viviam nestas condições até 2003 
foram alocadas em abrigos provisórios, tais como escolas, em casas improvisadas pela prefeitura, construídas em madeirite/compensado.

Os novos e pequenos conjuntos habitacionais construídos para abrigar os que moravam em condições denominadas "subhumanas" também passam a ser uma nova opção que transforma a paisagem dos bairros, porém muito mais onerosos para os que nada pagavam quando habitando por sobre o mangue. Ou seja, trata-se do início da política de financiamento da "casa própria" aos ex-moradores ocupantes do manguezal na baía de Vitória.

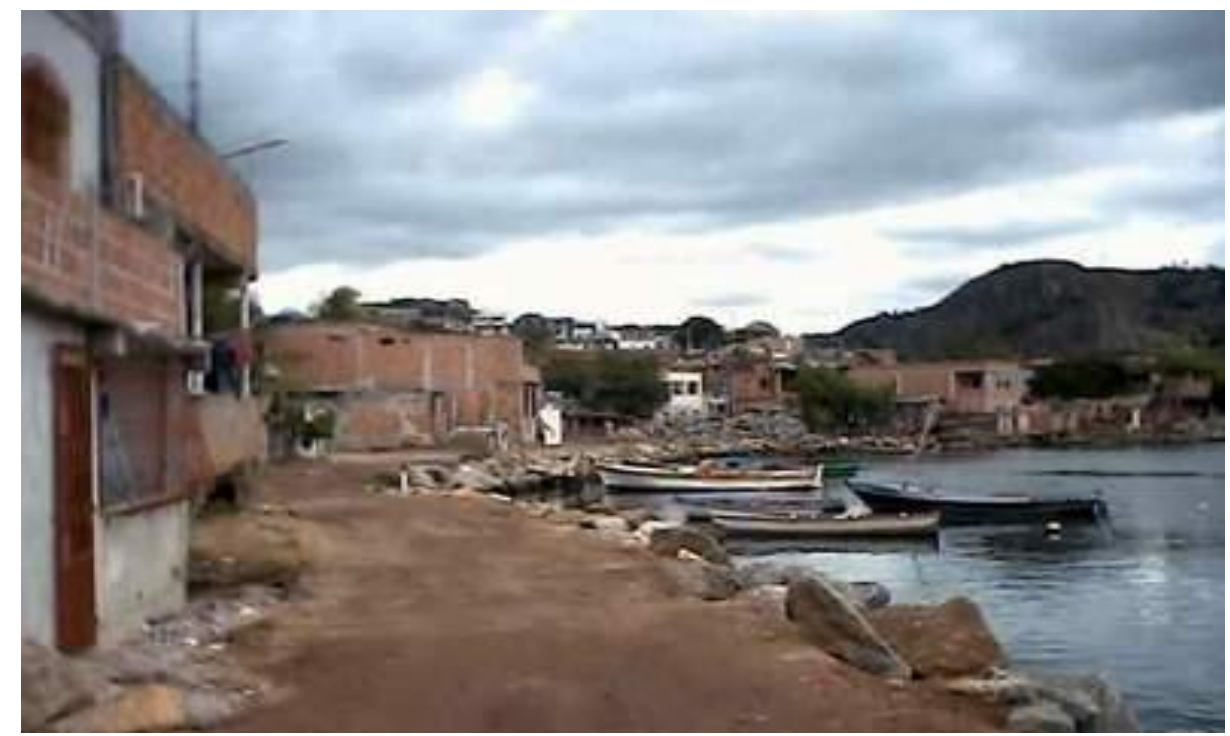

Figura 4 - O fim das palafitas: obras de aterro no bairro Andorinhas, destacando-se a contenção das águas do canal ligado à baía de Vitória. Foto: André Luiz N. Coelho/2004.

Em etapa posterior, as obras avançam em termos de arruamento e calçamento e os pequenos becos e ruelas vão dando lugar às novas ruas no interior dos mesmos. Chama a atenção as obras de aterro da baía, além da contenção das marés com enormes blocos de rocha, processo que antecede a criação de uma orla urbanizada. Ou seja, é o exemplo de como se dá a subtração do mar/da baía incorporando-os à cidade, agora como solo urbano (figura 4).

A rua, fruto do aterramento, circula a orla da baía, como uma espécie de "beiramar", dotada de ciclovia atende os trabalhadores que se utilizam de bicicleta, é também um atrativo para o lazer, assim como as micro praças, a iluminação pública, as calçadas para a caminhada, as grades de proteção entre a rua e a baia nos pequenos ancoradouros 
de barcos de pescadores que ainda residem nesses bairros, os quiosques, as quadras esportivas e outros equipamentos públicos coletivos (figuras 5 e 6).

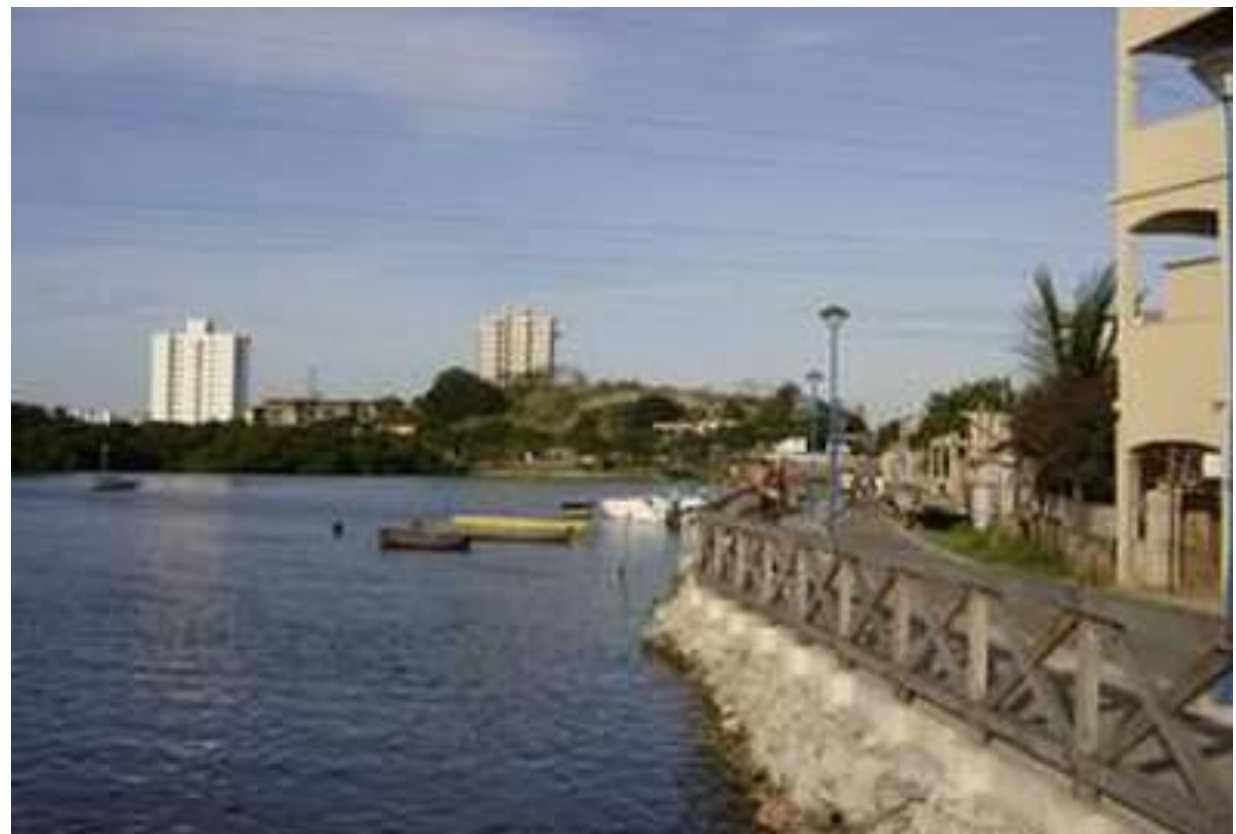

Figura 5 - Nova paisagem: projetos de urbanização no bairro Andorinhas com destaque para as grades em madeira junto ao canal, a pequena via de passagem e circulação de pedestres e a ciclovia.

Fotos: André Luiz N. Coelho/2005.

Nas entrelinhas da política de urbanização para os bairros que margeiam a baía (nas porções oeste, noroeste e norte) e o manguezal, pensada e implementada pelos governos municipal e estadual, principalmente, situam-se os interesses imobiliários, os negócios com a mercadoria espaço. A paisagem "natural" (dos mangues, da própria baía, o horizonte de montanhas visto a partir desses bairros, o bucolismo do lugar, as atividades tradicionais, etc.) são potenciais que apontam para uma "vocação" turística da região .

No âmbito da Agenda 21 e do Plano Estratégico de Vitória/Prefeitura Municipal, consta como um dos projetos prioritários para a cidade a consolidação da Rota Manguezal, que consiste na oferta de passeios turísticos por toda a baía de Vitória, circulando o manguezal e passando pelos bairros, o que exige criar e recuperar bases físicas para atracar esses barcos turísticos, criar pólos gastronômicos explorando a tradição da alimentação à base de mariscos e peixes, construção de praças/pontos de 
contemplação da paisagem, a recuperação de antigas construções, dentre outros projetos.

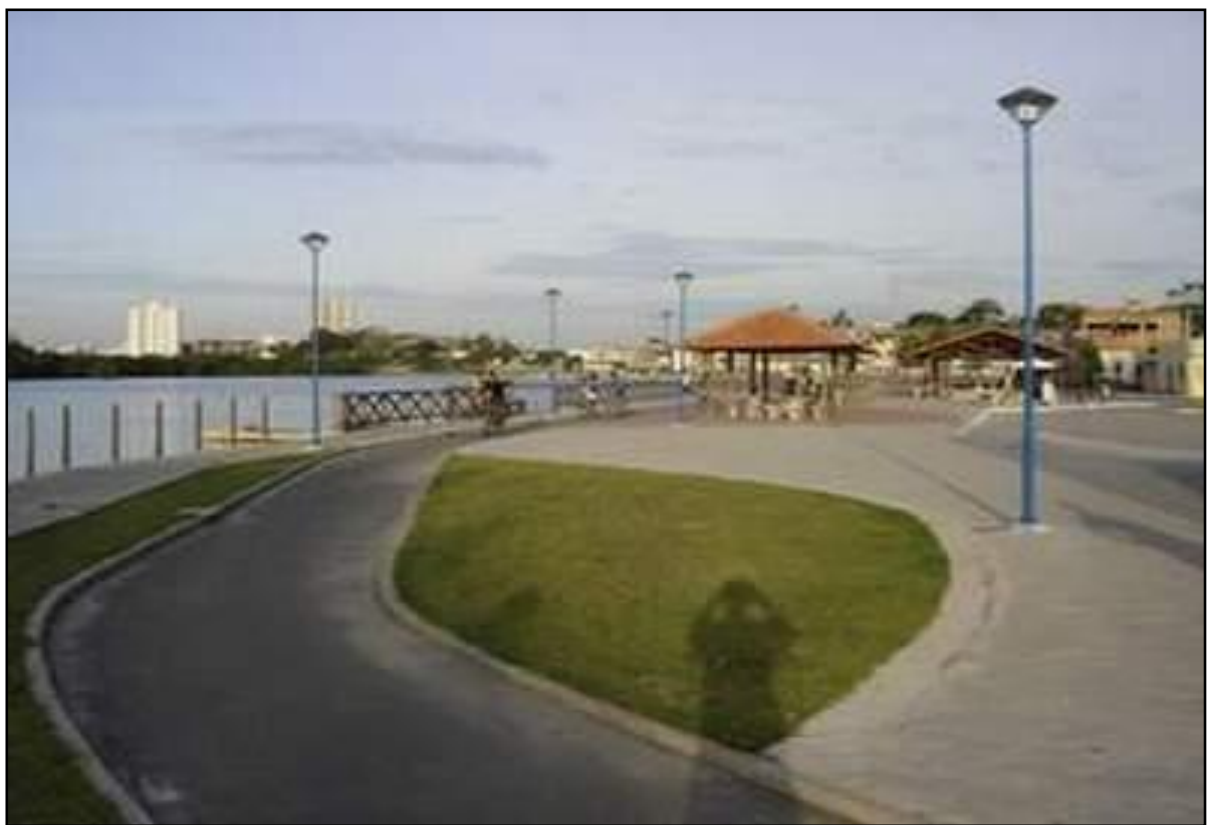

Figura 6 - Nova paisagem: projetos de urbanização que se repetem nos bairros Andorinhas, Santa Marta e Joana D'Arc, destacando-se os espaços livres, abrigos cobertos para jogos, ciclovia e iluminação.

Foto: André Luiz N. Coelho/maio de 2005.

Para o governo municipal, através de projetos como o Projeto Terra, trata-se de um novo momento para a região e, portanto, é hora de uma nova política respeitando a "vocação" da região, quer dizer dos bairros, pensando na "ocupação produtiva de seus espaços", isto é, potencializando o setor de serviços voltados para o turismo, a exemplo de restaurantes comunitários nos moldes do que já existe, e que envolvem comunidades locais, criando um certo "bucolismo" (a associação da paisagem dos bairros simples mas dotados de certa infra-estrutura somados à paisagem da baía junto ao manguezal) a ser apreciado pelos visitantes ${ }^{4}$.

Essa é uma nova realidade (e nova paisagem) voltada diretamente para os bairros que escolhemos para a pesquisa, mas que se incluem enquanto extensão/ampliação das políticas públicas de caráter "auto-sustentável" para as regiões

\footnotetext{
${ }^{4}$ Os moradores dizem já ocorrer com certa frequência a parada de barcos particulares - as lanchas - que saem em passeios nos finais de semana, não apenas dos de fora mas também moradores de bairros de classes médias altas que vêm a procurar de bares e restaurantes típicos no interior desses bairros.
} 
oeste, noroeste e norte da baía de Vitória, segundo consta nos projetos governamentais. A esse respeito Gurgel \& Pessali (2004, p. 123), destacam:

\begin{abstract}
A Região da Grande São Pedro tem um grande potencial turístico (...) $\mathrm{O}$ desenvolvimento desse potencial nos próximos anos está previsto no projeto Rota Manguezal, que quer avançar na questão ambiental e fazer de São Pedro um pólo de serviços de ecoturismo. Trata-se de um dos 31 projetos prioritários do Plano Estratégico de Vitória e integra a Agenda 21 local. O poder público entra como elemento indutor e estabelece a infra-estrutura. A iniciativa privada segue o projeto como agente promotor responsável por organizar e operar atividades e negócios.
\end{abstract}

Essa modernização via urbanização dos bairros e regiões inteiras, - novidades para os moradores - por atender demandas antigas são muito bem vindas; é motivo de pleno contentamento das comunidades que almejavam há tempos as obras de infraestrutura. A cada avanço da urbanização, a cada surgimento de novos equipamentos urbanos coletivos, o não abandono das obras ou a conclusão delas, tudo isso significa sempre amenizar a ansiedade e aguçar a perspectiva deles em residir num lugar que dessa forma, com as melhorias constituindo uma nova paisagem, parece, de fato, "fazer parte da cidade", como dizem.

Porém, se por um lado as pessoas se mostram satisfeitas com as melhorias, há, por outro, uma preocupação latente que é a especulação (com os lotes/terrenos e casas) dado a valorização dos bairros que recebe obras de infra-estrutura, equipamentos e embelezamento urbanos. Não menos importante, mas que está latente, também, são as mudanças de comportamento, de hábitos, de costumes, enfim do modo como os moradores agora fazem uso do espaço que se moderniza.

Que mudanças no tempo da vida o processo de urbanização recente trouxe para os moradores dos bairros de Vitória que escolhemos para a pesquisa? Como essas transformações vêm afetando o cotidiano das pessoas? Como a modernização do espaço permite novas possibilidades de apropriação e usos e elimina outras? Essas e outras são questões analisadas a partir das falas/depoimentos colhidos junto aos moradores e que fazem parte do material da pesquisa de campo ${ }^{5}$.

As associações de moradores dos bairros escolhidos para a pesquisa repassaram alguns documentos relativos ao processo de legalização dos lotes/residências, alguns processos e recortes de jornais acerca da remoção de moradores das palafitas para o 
interior dos bairros em caráter provisório, sugeriram alguns nomes de moradores mais antigos para os depoimentos e entrevistas, além de nos relatar sobre o andamento das obras e a participação das comunidades no processo. A princípio selecionamos 10 famílias/residências em cada um dos quatro bairros, cuja localização das mesmas nos possibilita fazer uma análise mais clara sobre as transformações físicas mais significativas, as quais influenciam e/ou afetam o cotidiano dos habitantes. Nessa etapa da pesquisa o grupo (orientadora e orientandos) optaram por tomar depoimentos dos moradores de modo que lhes fossem permitido falar a vontade sobre os seguintes temas/tópicos escolhidos e orientados por nós: as obras de urbanização; a valorização dos imóveis; os problemas que vem surgindo; as preocupações advindas dessas mudanças físicas e os ganhos e pontos positivos referentes às transformações. Esse trabalho não está pronto e continuamos com a pesquisa de campo.

Sobressaem nos depoimentos acerca das transformações oriundas das obras de urbanização/modernização nos bairros estudados, implementadas pela prefeitura como parte de grandes projetos urbanísticos, quatro pontos que merecem ser destacados e discutidos a seguir, quais sejam: a) os moradores aprovam e estão contentes com as melhorias realizadas até o momento; b) esperam a continuidade das obras relativas ao projeto como um todo ter continuidade independente das mudanças na administração municipal; c) os moradores introduziram mudanças no cotidiano a partir de novos usos que as novas áreas públicas coletivas (equipamentos urbanos) permitem, tais como caminhada, ginástica, lazer (jogos) e comércio e; d) apesar da satisfação que as melhorias urbanas permitem, os moradores não escondem a preocupação e inquietação com a especulação imobiliária que já ocorre e com o aumento da violência nos bairros.

É importante esclarecer, antes de analisarmos cada um desses pontos que, embora tenhamos muitos mais elementos para trabalhar em termos de construir um reflexão inicial sobre as perspectivas que estão postas para esses bairros e regiões que compõem a periferia de Vitória, nos detemos naquilo que salta aos olhos e que diz respeito a fenomenal mudança em tão pouco tempo nesses quatro bairros, os quais são pequenos, isto é, contam com pequena extensão, somando menos de 3 mil metros juntos ao longo do canais da baía. 
À respeito do contentamento dos moradores em relação às melhorias na oferta de infra-estrutura básica - arruamento, calçamento, redes de esgoto e água tratada -, assim como na oferta de equipamentos urbanos coletivos e embelezamento - pequenas praças, área de lazer, quadra esportiva, abrigo para jogos, iluminação especial, espaço para manobras de carros, jardins, assentos públicos, acostamentos em madeira, ciclovia e outros -, nas falas está claro que, conquanto a satisfação deles, não houve consultas, pedido de opiniões e sugestões por parte dos construtores aos diretamente atingidos pelas obras. Ou seja, os mesmos não foram ouvidos sobre o que e como fazer enormes transformações/operações urbanas nos bairros, ou como as demandas poderiam ser atendidas segundo as prioridades e desejos/sonhos dos moradores.

Conforme já mencionado anteriormente, as obras de urbanização/embelezamento sofreram uma paralização exatamente na mudança da administração municipal (final de 2006). Faz parte do Projeto Terra atingir todos os bairros ao longo da orla da baía norte até o encontro com a porção oeste, onde já foram concluídas em outra etapa, isto é, as 11 (onze) poligonais do projeto devem ser agraciadas segundo o plano original, e que teve início ainda na década de 90. Nesse sentido, os moradores salientam nos depoimentos a ansiedade e o desejo na continuidade das obras, especialmente aqueles que ainda não puderam usufruir "do novo espaço", mas também é o que esperam os habitantes que já gozam de novas ruelas, novas ruas, asfalto, calçamento..., uma vez que as conclusões significam aumentar novas possibilidades de lazer, de melhor fluxo entre os bairros (leia-se novas linhas de ônibus), expansão do comércio, etc.

É nos finais de semana e nos fins de tarde/ao anoitecer que se verifica o quanto novos hábitos, isto é, novas práticas surgiram e tendem a crescer enquanto parte do uso (ou usos) do novo espaço. Chama a atenção ao observar o movimento nos bairros, o que não diverge das falas dos moradores, o quanto as melhorias urbanas - a criação e ampliação de áreas - tem proporcionado mudanças no ritmo de vida dos mesmos. Exemplo disso é o aumento do lazer, da prática de esportes pelos jovens da quadra esportiva, as crianças brincando nas amplas áreas cimentadas, das caminhadas e ginástica diárias por parte de grupos denominados "terceira idade", do intenso uso da ciclovia pelos trabalhadores que se deslocam de casa para o trabalho e vice-versa, dos jogos de baralho nas mesas criadas para isso, dos jogos de bocha no espaço criado para 


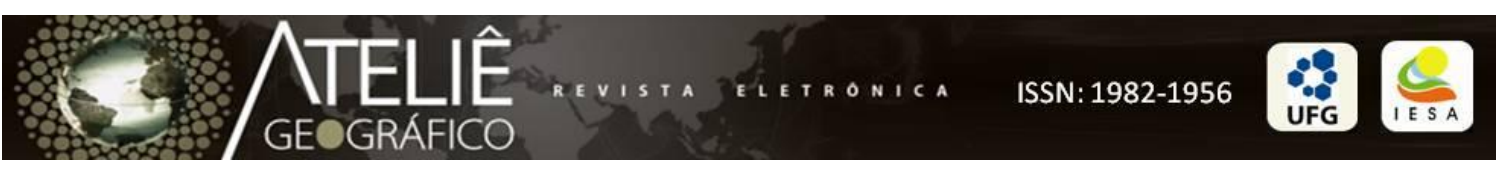

esse fim, etc., mas também surgiram nessas áreas livres públicas possibilidades de comércio, sobressaindo a venda de alimentos (bancas de comidas, pipoqueiros, doceiras, artesanato, etc.), além de produtos para uso de casa artesanais feitos pelas donas-de-casa (panos de prato, panos de decoração e similares). Percebe-se nos depoimentos que a tendência no aumento do comércio nas áreas dos novos equipamentos coletivos urbanos pode vir a ser complicado caso muitos moradores queiram e se achem no direito de montar/implantar algum tipo de comércio. Segundo alguns, provavelmente esse tipo de uso sofrerá em futuro breve restrições/regulamentações por parte da comunidade através das associações de bairro.

Com relação ao último ponto de destaque nos depoimentos dos moradores diz respeito às preocupações latentes deles, particularmente o medo no aumento da violência nos bairros e a especulação imobiliária. Quando indagados ou solicitados a falar sobre tais temas, fica claro que eles temem que as melhorias possam atrair para os novos espaços "estranhos" - malandros, aproveitadores, ladrões, traficantes, gente que vem fazer "zoação", como dizem -. Isso não significa que a violência, principalmente oriunda do tráfico de drogas não faça parte do cotidiano dos moradores há tempos. Contudo, pensar no aumento dessa violência é algo que tira o sossego deles.

Nas falas à respeito do tema aumento da violência é importante notar que os moradores já tomam as suas precauções, novas atitudes e até mudanças no dia-a-dia evitando estar vulnerável a algum tipo de ocorrência ou fato violento. Uma expressão dessa mudança no cotidiano é a permanência de mais tempo dentro de casa; é o evitar ficar exposto na rua, nos novos espaços, os quais no discurso foram construídos exatamente para permitir aumentar o lazer dos moradores.

Ainda no quisito preocupação/angústia, muitos moradores falam do aumento nas negociações de casas e lotes nos bairros, inclusive acentuam (e abominam) aqueles que foram capazes de vender/passar em frente casas que o projeto construiu para ser a nova moradia, retirando-os das palafitas em cima do mangue. Não é difícil no dia-a-dia testemunhar novos negócios imobiliários ou mesmo a ampliação (vertical) das residências mais antigas objetivando alugar quartos, "puxadinhos" e kitinetes. As obras de infra-estrutura e embelezamento trouxeram novas possibilidades para os moradores 
no que tange à valorização dos imóveis, o que os obriga a acabar a casa ${ }^{6}$, isto é, definir a construção, murar ou cercar, rebocar, pintar, arrumar o quintal, etc., pensando na futura necessidade de negociar o imóvel.

É interessante destacar que não raro nos deparamos com moradores que não participaram da ocupação do mangue e do início da constituição dos bairros, isto é, quatro entre as dez famílias de cada bairro que tivemos a oportunidade de entrevistar informaram que o imóvel foi adquirido/comprado de outros há pelo menos 12 anos enquanto a ocupação data do início dos anos 80 . Isso significa que a especulação com lotes e casas é um processo constante, mas que tem as suas especificidades. Chama a atenção o fato de que as famílias que tiveram sua renda aumentada ${ }^{7}$ nesse espaço de tempo consolidaram a permanência no lugar, iniciaram a construção da casa em alvenaria e continuaram a investir na moradia enquanto outros não conseguiram melhorar as condições necessárias para isso, não restando muita opção a não ser negociar o lote e a casa ainda em madeira ou o lote a ser regularizado pela prefeitura.

\section{Considerações Finais}

Esse texto que tem como objetivo se debruçar sobre uma análise da urbanização de bairros na periferia da cidade enquanto parte do processo de produção do espaço urbano, deixa propositalmente escapar nas entrelinhas o que é de extrema relevância no entendimento acerca da problemática urbana hoje: alguns aspectos, caminhos, processos e especificidades que apontam para a constituição de uma sociedade urbana que não abre mão desse tipo de "urbanização adequada", por um lado, e de outro, também como parte da constituição de uma sociedade urbana, a instalação de um modo de vida submetido e em conformidade com o mundo espetacular da mercadoria

Embora a impressão que se tem ao analisar as mudanças no ritmo e no cotidiano dos moradores dos bairros escolhidos para a pesquisa seja positiva e óbvia, isto é, parece, a princípio, que não há nada de extraordinário, questionável ou passível de

\footnotetext{
6 Nas áreas onde as obras já foram concluídas tem sido comum ver casas, fruto da auto-construção em estágio de acabamento e em ampliação vertical (2 e 3 andares), transformando-se em residências de mais de 100 metros quadrados, quando até pouco tempo antes de qualquer tipo urbanização, as casas pareciam estar sempre em processo de construção, sobressaindo o vermelho do tijolo.

7 O fator que mais sobressai nas falas é o aumento de mais membros da família (esposa e filhos) conseguindo emprego, o que contribui para a construção ou ampliação da casa.
} 
crítica, percebe-se uma tendência nos rumos que seguirá a vida nos bairros transformados pelas obras de modernização - a urbanização adequada segundo os idealizadores e implantadores -: os novos espaços têm pouco lugar para a espontaneidade e tendem a constituir-se em lugares de passagem e de circulação, conforme as observações e análises que realizamos.

Isso posto é preciso esclarecer um pouco mais à respeito. Como já mencionado anteriormente as principais obras que fazem parte desses projetos de urbanização denominados "adequados" resumem-se na criação de áreas/amplos espaços para uso coletivo, espécies de praças livres cimentadas/calçadas sem árvores, sem assentos, frios e áridos. Equipamentos que exigem ordem, limpeza, funcionalização e cujos usos precisam, em muitos casos, da adequação de usuários, isto é, novos comportamentos que devem incluir o controle do movimento das pessoas, os momentos e as restrições de uso, etc.

Quando os moradores atentam (com razão) para o aumento da violência, apesar de muitos pensarem que a urbanização, as melhorias físicas tendem a diminuir a violência, contraditoriamente percebe-se que a transformação de bairros simples em "bairros de classe média", segundo as falas dos moradores, afasta as pessoas da rua, retira o movimento que havia antes, diminui a freqüência pela apropriação dos lugares, enfim enfraquece a vida social, porque parece que as pessoas, as famílias se voltam para si próprias, para as suas residências. O que os indivíduos não percebem é que esses fatores certamente contribuem para aumentar a violência latente (e real), posto que ocorre um certo esvaziamento dos espaços públicos o que favorece a insegurança, abre possibilidades, por exemplo, para a instalação e as ações de grupos criminosos organizados, processo bastante freqüente nas cidades brasileiras.

Conquanto as muitas demandas sociais, as quais perpassam os pedidos por obras de urbanização, a construção de infra-estruturas urbanas e a dotação do espaço de equipamentos públicos coletivos em áreas destituídas de tudo isso, é preciso continuar pensando e afirmando que o direito à cidade significa, sim, mudar a vida, ter acesso a serviços urbanos, escolas, creches, hospitais, postos de saúde, acesso aos transportes coletivos, etc., mas esses direitos básicos não podem eliminar ou impossibilitar que o novo, os projetos modernizantes resultem em espaços que não possam ser apropriados sem a mediação do mercado, isto é, através de relações de troca mercantis. 


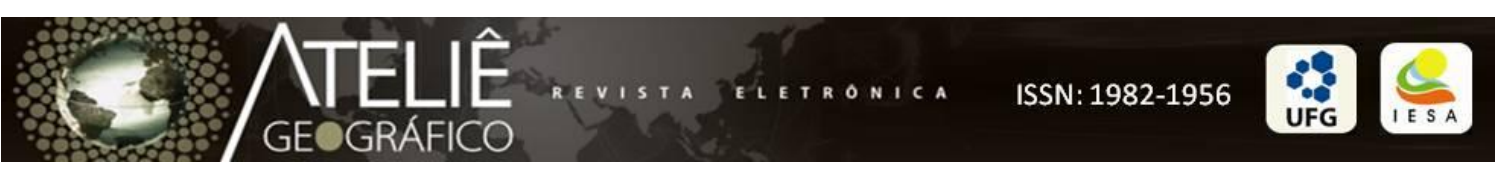

É importante reafirmar que políticas e projetos urbanos são criados, são conduzidas/implementadas sem discussões, sem a participação de moradores, isto é, pouco democráticos e, evidentemente atendendo a outros interesses. A pesquisa evidencia que é assim que o espaço urbano de Vitória, sobretudo a sua periferia, é produzido.

\section{Referências Bibliográficas}

ALVES, André. Os Argonautas do Mangue. Campinas-SP: Ed. Unicamp/Imprensa Oficial, 2004.

BENKO, George. Economia, Espaço e Globalização na Aurora do Século XXI. São Paulo: Ed. Hucitec, 1996, 266p.

CARLOS, Ana Fani A. A (Re)produção do Espaço Urbano. São Paulo: Edusp, 1994.

Espaço-Tempo na Metrópole: a fragmentação da vida cotidiana.

São Paulo: Ed. Contexto, 2001, 368p.

DAMIANI, Amélia L. "A Cidade (des)ordenada e o cotidiano". In: SILVA, José B. da; COSTA, Maria Clélia L.; DANTAS, Eustógio W. C. (Organizadores). A Cidade e o Urbano: temas para debates. Fortaleza-CE: Ed. UFC, 1997.

. "O urbano no mundo da mercadoria". In: CARLOS, Ana Fani A.

\& LEMOS, Amália I. G. (Organizadoras). Dilemas Urbanos. Novas abordagens sobre a cidade. São Paulo: Ed. Contexto, 2003.

FERNANDES, Ana C. Da Reestruturação Corporativa à Competição Entre Cidades: lições urbanas sobre os ajustes de interesses globais e locais no capitalismo contemporâneo. In: Espaço \& Debates, Ano XVII, 2001, número 41.

GOTTDIENER, Mark. A Produção Social do Espaço Urbano. Tradução de Geraldo Gerson de Souza. São Paulo: Edusp, 1993, 310p.

GURGEL, Antonio de P. \& PESSALI, Hésio (Coordenadores). São Pedro, Vitória. Um exemplo para o mundo. Vitória-ES: Contexto Jornalístico \& Assessoria Ltda/Instituto Huah; Instituto Histórico e Geográfico do Espírito Santo, 2004.

LEFEBVRE, Henri. La Production de l'espace. Paris, Anthropos, 1974.

A Revolução Urbana. Tradução de Sérgio Martins. Belo Horizonte: Ed. UFMG/Humanitas, 1999, 178p. 
LIMONAD, Ester. Urbanização e Organização do Espaço na Era dos Fluxos. In: Território Territórios - Programa de Pós-Graduação em Geografia-PPGEO. Niterói: UFF/AGB, 2002.

NUNES, André G. A. Os Argonautas do Mangue. Precedido de Balinese character (re)visitado/Etienne Samain. Campinas, SP: Editora UNICAMP; São Paulo: Imprensa Oficial do Estado, 2004.

SEABRA, Odette C. de L. Territórios do Uso: cotidiano e modo de vida. In: Revista Cidades Presidente Prudente-SP: Ed.Grupo de Estudos Urbanos-GEU. Vol. 1, Número 2, jul/dez 2004.

Prefeitura Municipal de Vitória-PMV. Projeto Terra (diversos mimeo).

SANTOS, Milton. Por uma outra globalização: do pensamento único à consciência universal. São Paulo: Ed. Record, 2000.

SIQUEIRA, M. da P. S. Industrialização e Empobrecimento Urbano. O Caso da Grande Vitória 1950-1980. Vitória: Edufes, 2001.

SOJA, E. W. Geografias Pós-Modernas: A Reafirmação do Espaço na Teoria Social Crítica. Rio de Janeiro: Jorge Zahar Editor, 1993.

Recebido para publicação em março de 2011. Aprovado para publicação em agosto de 2011. 